\title{
Kidney Dysfunction and Left Ventricular Assist Device Support: A Comprehensive Perioperative Review
}

\author{
Samuel T. Coffin ${ }^{a}$ Dia R. Waguespack ${ }^{b}$ Nicholas A. Haglund ${ }^{a}$ \\ Simon Maltais ${ }^{c}$ Jamie P. Dwyer ${ }^{b}$ Mary E. Keebler ${ }^{a}$ \\ Divisions of ${ }^{\mathrm{a} C}$ Cardiology, ${ }^{\mathrm{b}}$ Nephrology and ${ }^{\mathrm{C}}$ Cardiovascular Surgery, Vanderbilt University \\ Medical Center, Nashville, Tenn., USA
}

\section{Key Words}

Ventricular assist device $\cdot$ Kidney injury $\cdot$ Heart failure

\begin{abstract}
Left ventricular assist devices (LVADs) are used increasingly as a bridge to transplantation or as destination therapy in end-stage heart failure patients who do not respond to optimal medical therapy. Many of these patients have end-organ dysfunction, including advanced kidney dysfunction, before and after LVAD implantation. Kidney dysfunction is a marker of adverse outcomes, such as increased morbidity and mortality. This review discusses kidney dysfunction and associated management strategies during the dynamic perioperative time period of LVAD implantation. Furthermore, we suggest potential future research directions to better understand the complex relationship between renal pathophysiology and mechanical circulatory support.
\end{abstract}

(c) 2015 S. Karger AG, Basel

\section{Epidemiology of Heart Failure and Acute Kidney Injury}

Advanced heart failure (HF) is common in the United States, affecting an estimated 5.1 million patients and comprising more than $2 \%$ of the total population [1]. HF is the leading cause of hospitalization in patients over the age of 65 years, and among these hospitalized patients, most have chronic kidney disease [CKD; estimated glomerular filtration rate (eGFR) $\left.<60 \mathrm{ml} / \mathrm{min} / 1.73 \mathrm{~m}^{2}\right]$ stage 3,4 , or $5[1,2]$. Acute kidney injury (AKI) is observed in $>50 \%$ of the patients admitted with acute decompensated HF and in $>70 \%$ of the patients diagnosed with cardiogenic shock [3]. The combination of acutely decompensated HF admission and AKI (regardless of baseline renal function) is strongly associated with adverse outcomes, including an increased hospital length of stay and death during the index hospitalization [4]. 


\section{CardioRenal} Medicine

\begin{tabular}{l|l}
\hline Cardiorenal Med 2015;5:48-60 \\
\hline DOI: 10.1159/000369589 & $\begin{array}{l}\text { @ 2015 S. Karger AG, Basel } \\
\text { www.karger.com/crm }\end{array}$ \\
\hline
\end{tabular}

Coffin et al.: Kidney Dysfunction and Left Ventricular Assist Device Support: A Comprehensive Perioperative Review

\begin{tabular}{ll}
\hline Score & Clinical status \\
\hline 1 & Critical cardiogenic shock \\
2 & Progressive decline \\
3 & Stable but inotrope-dependent \\
4 & Resting symptoms \\
5 & Exertion-intolerant \\
6 & Exertion-limited \\
7 & Advanced NYHA class 3 \\
\hline
\end{tabular}

\author{
Critical cardiogenic shock \\ Progressive decline \\ Resting symptoms \\ Exertion-intolerant \\ Exertion-limited
}

system [6]

Table 1. INTERMACS scoring system $[6]$

\section{Overview of Left Ventricular Assist Devices}

Treatment options for patients with advanced HF unresponsive to medical therapy are limited to heart transplantation, durable mechanical circulatory support, and palliative care. Unfortunately, the limited number of donor hearts available for transplantation has resulted in a relatively fixed number of transplantations $(n=2,400)$ performed annually in the United States [5]. Consequently, many patients who qualify for heart transplantation never receive a donor organ. Additionally, many patients with advanced HF and a failure of optimal medical therapy are not candidates for heart transplantation due to advanced age, obesity, or complications from long-standing diabetes [3]. The widening gap between the number of patients with advanced HF who qualify for transplantation and the shortage of donor hearts has led to the increased utilization of left ventricular assist device (LVAD) therapy as a bridge to transplantation or as destination therapy for those patients who are not transplantation eligible. In 2013, the annual number of durable LVAD implantations surpassed the number of heart transplantations performed in the United States, with over 2,500 LVADs implanted. In addition, implant trends strongly favor an increased LVAD utilization in the future [6]. The two most commonly used contemporary LVADs are the HeartMate II (HMII) and HeartWare (HW) devices. The HMII is an axial flow rotary pump, while the HW is a centrifugal flow pump. These pumps generate an output capacity of up to $10 \mathrm{l} / \mathrm{min}$ and are traditionally surgically placed via a median sternotomy to provide full circulatory support. The deviceheart interface is complex and requires constant attention to volume status and intrinsic myocardial function as well as careful adjustment of device parameter settings. Pulsatile flow LVADs (PF-LVADs), while no longer routinely used in the contemporary era for left ventricular (LV) support, were historically important in the development of the currentgeneration continuous flow LVADs (CF-LVADs), such as the HMII and HW device types. Compared to the older pulsatile pumps, CF-LVADs have resulted in a significant improvement in the adverse event profile, including a reduction in the rates of infection, right ventricular (RV) failure, mechanical device complications, respiratory failure, kidney dysfunction, arrhythmia, and mortality [7].

The decision to implant LVADs is complex and based on patient comorbidities, estimation of the waiting time to heart transplantation for bridge-to-transplantation candidates, estimation of reversibility of end-organ dysfunction, specifically kidney dysfunction, and assessment of psychosocial factors [8, 9]. Greater experience related to patient selection and operative and perioperative LVAD management has led to an improved understanding of the effects of continuous flow physiology on kidney function. To this end, the Interagency Registry for Mechanically Assisted Circulatory Support (INTERMACS) scoring system was created to differentiate between HF disease severity and perceived urgency of mechanical device support (table 1) [10]. This scoring system has proven helpful when evaluating patients for 
Coffin et al.: Kidney Dysfunction and Left Ventricular Assist Device Support:

A Comprehensive Perioperative Review

possible device candidacy. However, many questions about patient selection and timing of CF-LVAD implantation remain unanswered. This review focuses on the complex interaction of LVAD physiology and kidney function, including the prevention and management of kidney dysfunction.

\section{What Effect Does LVAD Physiology Have on Kidney Function?}

The effect of LVAD therapy on kidney function and physiology has been studied recently with conflicting results and without a clear pathophysiological understanding [11-19]. One current limitation to studying this pathophysiology is that LVAD implantation trends have changed from historically pulsatile to exclusively continuous flow device types. Research on pulsatile device types and kidney function may have limited their generalizability to contemporary-era CF-LVAD patients. Historical physiological studies in patients who received PF-LVAD therapy have demonstrated improved systemic perfusion [20] and decreased levels of renin, aldosterone, and vasopressin [21]. Welp et al. [12] demonstrated that the renin levels improved in PF-LVAD and CF-LVAD patient groups, but the improvement was more marked in the PF-LVAD group. Initial clinical studies focused on the effect of LVADs on kidney function over the first 3-12 months after device implantation. These studies reproducibly showed an improvement in GFR and other measures of kidney function over the first 4-6 months after LVAD implantation [22-26].

In contrast, CF-LVADs result in continuous flow physiology and increased diastolic pressures. An increased diastolic pressure is a key difference that, in combination with RV failure and venous congestion, could be critical in the development of kidney dysfunction. Despite the relatively fixed impeller speeds in CF-LVADs, there is a variable degree of pulsatile blood flow generated from the residual effects of native myocardial contractility [16, 17]. Overall, the circulatory effects of CF-LVAD support result in an increased systemic mean arterial pressure and improvements in kidney perfusion [18]. However, Park et al. [27] have demonstrated that, despite early improvements in eGFR, there is a progressive decline in kidney function during CF-LVAD support. There is also a low incidence of an initial worsening of kidney function after LVAD placement, with several trials showing an AKI incidence of $10 \%$ during the first month after implantation, and in these patients, there is a low chance of eventual recovery of kidney function $[22,28]$. Other recent studies have shown an AKI rate of up to $28 \%$ in CF-LVAD patients [22, 27, 29-31].

Further complicating this issue are animal studies showing that subjects implanted with CF-LVADs with intact LV function experienced negative renal effects, including renal arterial smooth muscle hyperplasia, inflammatory infiltration of the periarterial areas, and development of interstitial nephritis [13-15]. Recent studies focusing on homogeneous CF-LVAD populations have shown an initial improvement in kidney function in patients with both baseline normal eGFR and baseline impaired eGFR, followed by a slow decline in renal function over 6-12 months after device implantation [22, 32]. Despite the progressive late decline in eGFR, the final eGFR measured at 6 and 12 months was still significantly improved compared to the baseline pre-implantation values. Brisco et al. [28], despite confirming an early eGFR improvement, showed that the 1-year improvement in post-implantation eGFR was only $6.7 \%$ above the pre-implantation function. The same study also found that reduced survival after CF-LVAD implantation was associated with any change in eGFR (increase or decrease). Together, these studies suggest a complex and evolving relationship between initial eGFR increases related to improved hemodynamics and the potential chronic detrimental effects of continuous flow physiology on kidney function. 


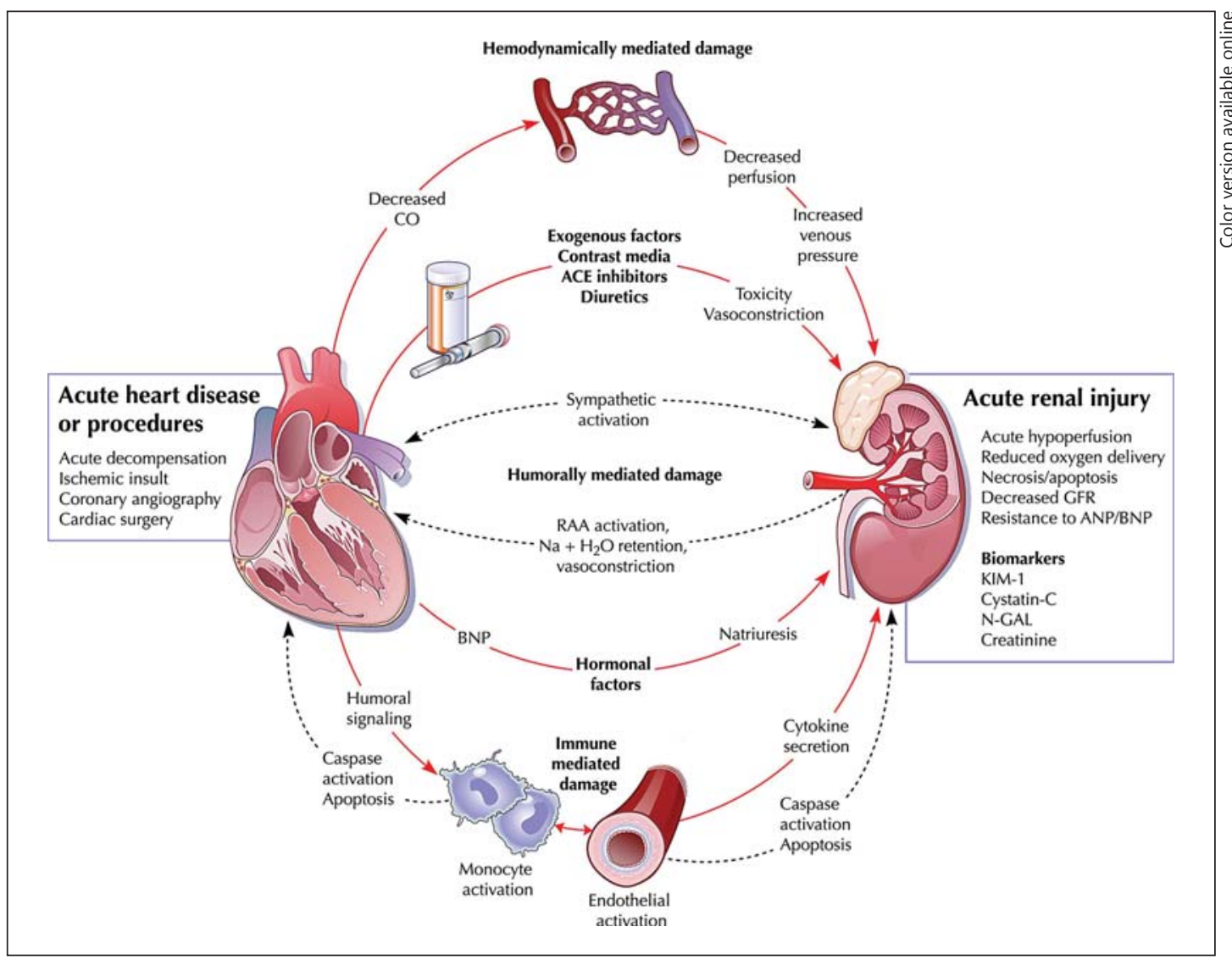

Fig. 1. The pathophysiology of interactions between the heart and kidneys in cardiorenal syndrome type 1 . ANP = Atrial natriuretic peptide; BNP = brain natriuretic peptide; $\mathrm{CO}$ = cardiac output; KIM = kidney injury molecule; RAA = renin-angiotensin-aldosterone. Figure illustration by Rob Flewell. Reprinted from Ronco et al. [74] with permission.

\section{Kidney Dysfunction and HF}

Kidney dysfunction associated with HF is a growing epidemic, occurring in nearly two thirds of hospitalized patients with HF [2, 4]. Kidney dysfunction may be related to intrinsic disease from long-standing comorbidities or from fluctuating acute and chronic hemodynamic changes causing venous congestion and poor renal perfusion. Cardiorenal syndrome types 1 and 2 are commonly identified in patients with advanced HF and reflect a decrease in cardiac output resulting in poor kidney perfusion, reduced renal autoregulation, increased renin-angiotensin system activation, and renal arterial vasoconstriction (fig. 1) [33, 34]. While decreased cardiac output leads to decreased kidney perfusion, the effects of systemic venous congestion, which further impairs renal blood flow and is associated with worsening kidney function, are equally important $[11,12]$. Renal parenchymal disease worsens over time with repeated AKI events, oxidative stress, and inflammation resulting in an eventual progression to intrinsic CKD [35]. Medications such as angiotensin-converting enzyme inhibitors (ACE-Is), angiotensin receptor blockers (ARBs), intravenous contrast used in diagnostic angiography or radiologic studies, and diuretics may also contribute to acute and chronic renal dysfunction in decompensated HF patients [36-38]. Anemia, recurrent infections, and 


\section{CardioRenal Medicine}

Table 2. Pre- and intraoperative factors that predict postoperative AKI

\begin{tabular}{l|l}
\hline Cardiorenal Med 2015;5:48-60 \\
\hline DOI: 10.1159/000369589 & $\begin{array}{l}\text { ( ) 2015 S. Karger AG, Basel } \\
\text { www.karger.com/crm }\end{array}$ \\
\hline
\end{tabular}

Coffin et al.: Kidney Dysfunction and Left Ventricular Assist Device Support: A Comprehensive Perioperative Review

Preoperative factors

INTERMACS score 1 or 2

Kidney $<10 \mathrm{~cm}$ in size

Older age

ACE-I or ARB therapy immediately prior to surgery

High central venous pressure

Low LV end-diastolic dimensions

Intraoperative factors

Longer cardiopulmonary bypass time

$>1$ liter blood loss

Need for reoperation within $48 \mathrm{~h}$

Sepsis

Liver dysfunction

Blood transfusion

an increased inflammatory state commonly seen in patients with decompensated HF may also increase the risk of renal dysfunction [39]. Identifying the underlying contributors to kidney dysfunction is paramount in predicting the potential reversibility of kidney dysfunction prior to LVAD implantation or cardiac transplantation.

\section{Kidney Dysfunction prior to LVAD Placement}

As discussed previously, kidney dysfunction in patients with advanced HF is often due to a combination of intrinsic parenchymal disease and potentially reversible hemodynamic abnormalities. Multiple studies have shown that survival outcomes are worse after both CF-LVAD placement and cardiac transplantation in patients with preexisting and continuing kidney dysfunction. One study noted a $27 \% 6$-month mortality in patients with eGFR $>60 \mathrm{ml} /$ $\mathrm{min} / 1.73 \mathrm{~m}^{2}$ prior to implantation compared with a $52 \%$ mortality in patients with eGFR $<60$ $\mathrm{ml} / \mathrm{min} / 1.73 \mathrm{~m}^{2}$ [24]. A Japanese study demonstrated survival rates of $96.2 \%$ at 30 days, $88 \%$ at 90 days, and $77.5 \%$ at 1 year after implantation in patients with pre-implantation creatinine levels $<1.96 \mathrm{mg} / \mathrm{dl}$ compared to survival rates of $60,46.7$, and $31.1 \%$, respectively, in patients with pre-implantation creatinine levels $>1.96 \mathrm{mg} / \mathrm{dl}$ [31]. Kidney dysfunction (eGFR $<45 \mathrm{ml} / \mathrm{min} / 1.73 \mathrm{~m}^{2}$ ) prior to implantation has also been shown to negatively affect posttransplantation survival in patients supported with LVAD as a bridge to transplantation [19]. Although the choice of LVAD or inotropic support in status 1B patients did not affect overall post-transplantation survival, patients who were implanted with LVADs and had an eGFR $<45$ $\mathrm{ml} / \mathrm{min} / 1.73 \mathrm{~m}^{2}$ had inferior heart transplantation survival outcomes. These studies paint a troubling picture for clinical outcomes in patients with kidney dysfunction prior to surgery.

Recent efforts have focused on identifying preoperative characteristics that predict postoperative kidney function in CF-LVAD populations (table 2). Hasin et al. [22] identified positive and negative pre-implantation predictors of postoperative kidney function in 83 patients implanted with a HMII CF-LVAD. Independent predictors of improvement in kidney function included atrial fibrillation at baseline, an increase in GFR with proper medical therapy prior to implantation, and intra-aortic balloon pump placement prior to implantation. Predictors of poor kidney function included 1 or more kidneys $<10 \mathrm{~cm}$ in size, older age (not defined further), and ACE-I or ARB therapy prior to surgery. Additionally, patients with higher central venous pressures and lower LV end-diastolic dimensions before LVAD implantation (markers of RV dysfunction) had an increased risk of postoperative AKI [40]. 
Coffin et al.: Kidney Dysfunction and Left Ventricular Assist Device Support:

A Comprehensive Perioperative Review

These predictors may be related to poor baseline kidney function or simply could be markers of a higher-risk operative group. In patients with baseline moderate to severe renal dysfunction (CKD stages 3-4), observing a favorable end-organ response to aggressive hemodynamic optimization - including inotrope and temporary mechanical support if indicated - is necessary to determine whether the patient is a candidate for durable mechanical circulatory support [41].

\section{Kidney Dysfunction due to Operative Factors}

While operative characteristics are important in predicting postoperative kidney dysfunction, only historical data from the PF-LVAD era are available. Alba et al. [42] sought to identify predictors of AKI by comparing 24 patients who developed AKI after PF-LVAD implantation with 29 patients who did not develop AKI. The baseline kidney function was similar between the groups. The patients with significant postoperative AKI were noted to have longer cardiopulmonary bypass times ( $122 \pm 55$ vs. $78 \pm 17 \mathrm{~min}$ ), higher intraoperative bleeding ( $>1$ liter blood loss in 68 vs. 32\%), and a higher need for reoperation (58 vs. 24\%). Patients who developed AKI were also noted to have higher rates of sepsis, liver dysfunction, blood transfusions, RV failure (73 vs. 30\%), and ventricular tachycardia [42]. It is difficult to determine whether these findings in a PF-LVAD population are generalizable to contemporary CF-LVAD operative characteristics and kidney dysfunction. Efforts have been made at our institution to decrease or even eliminate cardiopulmonary bypass time, perform less invasive surgical device implantations to avoid traditional sternotomy, and to minimize blood product utilization in order to improve postoperative outcomes, including kidney dysfunction. Research focusing on the CF-LVAD operative time period may identify critical variables that influence functional outcomes and allow the development of therapeutic strategies to minimize postoperative kidney dysfunction.

\section{Kidney Dysfunction in the Postoperative Period}

Patients who receive LVAD implantation have a significant early improvement in kidney function, while a minority experience AKI. AKI in the postoperative period is known to be a negative predictor of outcomes after PF-LVAD implantation [43] and has been associated with an increased 1-year mortality in CF-LVAD recipients (relative risk 3) [44].

Despite renal adaptation to a nonphysiological continuous flow pattern and a significant functional improvement in kidney function during the first month, the initial postoperative period can be hostile for the kidneys [22, 32]. Factors such as acute blood loss, volume shifts, arrhythmias, and the effect of multiple vasoactive medications influence renal hemodynamics. The sudden change in renal blood flow characteristics due to CF-LVAD support can lead to AKI [45]. Patients with preoperative RV failure and patients with INTERMACS scores of 1 or 2 are at higher risk of AKI [6]. Yoshioka et al. [31] showed that $29.3 \%$ of INTERMACS 1 patients required renal replacement therapy (RRT) in the postoperative period as compared to 7\% of INTERMACS 2 and 3 patients. The RV function is of vital importance after LVAD placement since postoperative RV failure and idioventricular arrhythmias have been associated with AKI [42]. An RV dysfunction can result in a reduced LV preload, low LVAD speeds, reduced forward flow, increased arrhythmias, and liver as well as kidney congestion. AKI in the postoperative period is a significant risk for newly implanted patients, and the management in this time period is crucial to reduce potential morbidity and mortality. 


\section{Management of AKI after LVAD Implantation}

An aggressive management of AKI in the postoperative period is essential to reduce the risk of long-term dialysis. RRT after LVAD placement has been associated with increased morbidity and mortality, and CKD is correlated with post-transplantation mortality in patients bridged with LVAD $[5,6]$. The initial management of postoperative AKI is primarily directed toward optimizing the intravascular volume, maintaining the goal mean arterial pressure, balancing the use of inotropic and vasopressor medications, and optimizing RV systolic function. This must all occur while also maintaining LVAD function and facilitating surgical recovery.

The management of the optimal intravascular volume is of paramount importance in patients with CF-LVADs given the sensitivity of the devices to preload and afterload conditions. In the event of AKI, frequent volume status assessments guide decisions regarding corrective therapy. Should intravascular volume be required, mechanical circulatory support guidelines recommend an infusion of packed red blood cells or colloid (5\% albumin) [41]. However, renal guidelines recommend crystalloid in response to AKI, which is typically used as second-line therapy in CF-LVAD patients who are frequently vasoplegic postoperatively and rapidly lose fluid to the interstitium $[46,47]$. In contrast, a high central venous pressure can result in a decreased kidney function due to increased venous congestion and edema ('nephrosarca') [39, 48]. General CF-LVAD recommendations include maintaining a goal central venous pressure of 4-14 $\mathrm{mm} \mathrm{Hg}$ to preserve euvolemic intravascular volume and minimize the risk of venous congestion [41]. However, care should be taken in the context of $\mathrm{RV}$ dysfunction, which may require higher preload conditions to maintain optimal RV preload. Diuretic therapy must be carefully titrated to maintain the optimal volume status. Overly aggressive diuretic use can cause low-flow CF-LVAD states and possible pump 'suck down' events, whereas inadequate diuretic therapy may exacerbate RV dysfunction and cause hepatic and renal congestion. Occasionally, due to severe or prolonged kidney congestion states, diuretic resistance leads to ineffective diuretic therapy and the need for active volume removal with ultrafiltration [41].

Current LVAD treatment recommendations advise maintaining a mean arterial pressure of 65-90 mm Hg [41]. The upper limit is in place to reduce intracerebral vascular event rates, reduce afterload to optimize LVAD function, and reduce the risk of pump thrombus [49, 50]. We recommend keeping the lower limit above 55-60 mm Hg given the relationship between hypotension and AKI [51]. During the immediate postoperative time period, mean arterial pressures $>90 \mathrm{~mm} \mathrm{Hg}$ should be treated with intravenous hydralazine or nitroglycerin as nitroprusside is contraindicated in AKI. For chronic blood pressure control, we prefer the use of afterload-reducing agents like ACE-Is or ARBs. Trials have unambiguously demonstrated that treatment with ACE-I or ARB medications delays the progression of CKD [52-54]. We have also successfully used isosorbide mononitrate and hydralazine oral therapy, although there is a low risk of ANCA vasculitis affecting the kidney [55]. We generally avoid betablocker use in the immediate postoperative time period to reduce the risk of negative inotropic effects in patients with significant RV dysfunction.

Patients who receive LVADs require vasopressor and inotropic therapy during the postoperative period. In this acute period, we generally prefer vasopressin for blood pressure support and attempt to minimize the use of norepinephrine. Epinephrine, milrinone, and inhaled epoprostenol are used to maintain RV function and LV preload [41]. This combination is generally weaned to milrinone only by postoperative day 5 . Our institution has recently demonstrated that plasma milrinone levels were significantly higher in patients with low eGFR than in patients with normal eGFR and were frequently above the recommended plasma blood levels [56]. Based on these findings, in patients with eGFR $<30 \mathrm{ml} / \mathrm{min} / 1.73 \mathrm{~m}^{2}$, we 
Coffin et al.: Kidney Dysfunction and Left Ventricular Assist Device Support: A Comprehensive Perioperative Review

recommend a $50 \%$ dose reduction in intravenous milrinone. We are currently studying the use of inhaled milrinone to better understand milrinone pharmacokinetics in patients with advanced HF and renal dysfunction (ClinicalTrial.gov identifier: NCT02077010).

$\mathrm{RV}$ failure is a common adverse event in the postoperative period and can result in the inability of the pulmonary circulation to provide the LVAD with adequate preload, despite medical therapy with inotropes. As RV failure develops, the dysfunctional RV is unable to provide the left ventricle with adequate preload, setting off a cascade of adverse hemodynamic events consisting of a progressive decrease in LV cavity size, decreased LVAD flow, and decreased systemic and renal blood flow. With this reduced LVAD flow, venous congestion develops and contributes to worsening renal function, decreased urine output, and a positive feedback loop that further worsens the already compromised RV function. The options for the management of RV failure are dependent on the underlying etiology. Guidelines recommend inotropic support, early diuretics, continuous RRT (CRRT) to maintain euvolemia, and treatment of pulmonary hypertension [41]. In addition, maintaining appropriate oxygenation and ventilation and optimizing device parameters to minimize excessive leftward interventricular septal shift is crucial to support RV function [50]. In unrecoverable cases, early surgical RV assist device placement may be required either temporarily or permanently.

CRRT or intermittent hemodialysis options may be chosen for patients requiring hemodialysis for postoperative AKI. A Cochrane analysis comparing CRRT to intermittent hemodialysis in AKI patients concluded that outcomes were similar in terms of mortality, length of hospitalization, and eventual recovery of renal function [57]. Unfortunately, randomized controlled trials comparing CRRT and intermittent hemodialysis in surgical intensive care unit patients or specifically LVAD patients do not exist. While CRRT is associated with increased costs and more adverse events in intensive care unit patients, this therapy may be particularly advantageous in a CF-LVAD population due to minimization of large fluid shifts and consistent volume control and solute concentration [58]. There is no intrinsic difference in dialysis management in LVAD patients when compared to other patients who require dialysis, and for this reason, the dose of CRRT needed is equivalent to that for other intensive care unit patients, which has been shown in multiple studies to be $20-30 \mathrm{ml} / \mathrm{kg} / \mathrm{h}$ $[59,60]$. Likewise, the reasons for starting dialysis are identical to those in other patients and include volume overload not improving with medications, hyperkalemia, acidosis, and solute control.

In our practice, we define post-LVAD AKI that persists for 30 days as end-stage renal disease and thus are able to plan for outpatient dialysis. The ability to measure blood pressure is vital to successful dialysis; CF-LVAD patients who are not pulsatile may require blood pressure measurements with a Doppler device. The quick removal of intravascular volume can result in decreased flow parameters of the device, potentially requiring adjustments of ultrafiltration targets during an individual dialysis session. Peritoneal dialysis (PD) is an interesting option to be considered to minimize sudden volume shifts. However, frequent manipulation of the PD catheter and its close approximation to the CF-LVAD driveline raise concern for an increased infection risk. To our knowledge, there are 2 case reports showing the successful use of PD in 2 LVAD patients, and we plan to consider the use of PD as a future direction for our LVAD and dialysis programs [61, 62].

When LVAD patients require RRT, the choice of access is led by several factors. Data from the United Network for Organ Sharing (UNOS) database demonstrate that the number of heart-kidney transplantations has increased from 30 in the year 2000 to over 70 a year in 2011 [63]. For patients supported with CF-LVAD as a bridge to transplantation who have a reasonable possibility of dual heart-kidney transplantation, a temporary access with a tunneled catheter is reasonable as it avoids a more complex surgical procedure to place a 
Coffin et al.: Kidney Dysfunction and Left Ventricular Assist Device Support:

A Comprehensive Perioperative Review

fistula or graft. However, in CF-LVAD patients who receive implantation as destination therapy and who require RRT, permanent dialysis access should be considered. Regardless of the access site, RRT carries a significant burden of clinically significant bacteremia with repeated dialysis events [64]. Due to intravascular hardware, LVAD patients must be assumed to have a higher risk of intravascular infection than other patients.

\section{Future Directions}

Patient selection is an evolving field. As new markers of renal dysfunction gain popularity and research backing, we may be able to better predict those patients with intrinsic kidney disease that will not improve with LVAD support. One such example is neutrophil gelatinaseassociated lipocalin (NGAL), a serum biomarker. In a small cohort of patients who received LVAD implantation, those patients with AKI requiring RRT had higher levels of NGAL compared to both those with AKI who did not require RRT and those without AKI [65]. This improved patient selection may decrease postoperative kidney dysfunction and subsequent mortality. There is also a trend towards implanting patients with higher INTERMACS scores in an effort to prevent irreversible end-organ damage in the time period prior to LVAD placement [6]. This strategy is currently under investigation in 2 randomized controlled clinical trials $[66,67]$.

Full circulatory support, meant to replace rather than assist intrinsic heart function, has been the focus of contemporary CF-LVAD management in patients with decompensated HF. As the devices become smaller and healthier patients are considered for LVAD implantation, the option of partial support becomes more realistic. To this end, devices that supply only partial support (3-4 l/min of flow) are being developed [68]. This may allow implantation earlier in the course of HF and may also help prevent irreversible end-organ dysfunction. We have also explored the implantation of the LVAD outflow cannula in the descending aorta and the subclavian artery, which accomplishes a similar goal of limiting flow but still offering significant circulatory support as well as providing more options for anastomosis if the ascending aorta is unavailable [69].

As noted earlier, initial studies comparing changes in renin-angiotensin levels in response to pulsatile and continuous flow devices noted more improvement in the pulsatile category. It is also known that CF-LVAD patients have a high rate of gastrointestinal bleeding due to arteriovenous malformations that were not present in PF-LVAD populations [70]. To this end, newer devices such as the HeartMate III and the Evaheart system incorporate some pulsatility in their functioning. This hybridization of continuous flow and pulsatile physiology may help decrease the detrimental effects of continuous flow physiology on the kidneys without the mechanical complications of the first-generation PF-LVADs.

We are currently comprehensively assessing the relationship between perioperative patient characteristics and the development of postoperative AKI. Important data could be gleaned from future analysis of the INTERMACS database with regard to the relationship between AKI and RRT after LVAD placement as well as eventual postoperative outcomes. Eventually, large-scale randomized controlled trials should be performed to improve the knowledge of pre-implantation risk factors of postoperative AKI and CKD as well as of intraoperative and postoperative management strategies.

There have been multiple reports of LVAD exchange via minimally invasive left anterior thoracotomy procedures [71-73]. Because of these successes, our institution has begun implanting LVADs without cardiopulmonary bypass and via left anterior thoracotomy combined with a small right hemisternotomy in order to decrease intraoperative risk factors of poor outcomes. Our initial experiences have been positive, and as our experience grows, we will be able to better evaluate mortality and kidney dysfunction in the postoperative period. 


\section{CardioRenal Medicine}

\begin{tabular}{l|l}
\hline \multicolumn{2}{l}{ Cardiorenal Med 2015;5:48-60 } \\
\hline DOI: $10.1159 / 000369589$ & $\begin{array}{l}\text { C) 2015 S. Karger AG, Basel } \\
\text { www.karger.com/crm }\end{array}$ \\
\hline
\end{tabular}

Coffin et al.: Kidney Dysfunction and Left Ventricular Assist Device Support: A Comprehensive Perioperative Review

\section{Conclusion}

Kidney function after CF-LVAD placement is an extremely important determinant of short- and long-term morbidity and mortality and can be a barrier for hospital discharge. Recognizing and modifying pre-, intra-, and postoperative risk factors for kidney injury is crucial for improving outcomes. Ongoing research, the emergence of new pump prototypes, and changing surgical techniques may drastically reduce the rates of kidney injury and improve mortality in the near future.

\section{References}

$>1$ Go AS, Mozaffarian D, Roger VL, Benjamin EJ, Berry JD, Borden WB, Bravata DM, Dai S, Ford ES, Fox CS, Franco S, Fullerton HJ, Gillespie C, Hailpern SM, Heit JA, Howard VJ, Huffman MD, Kissela BM, Kittner SJ, Lackland DT, Lichtman JH, Lisabeth LD, Magid D, Marcus GM, Marelli A, et al: Executive summary: heart disease and stroke statistics - 2013 update: a report from the American Heart Association. Circulation 2013;127:143-152.

-2 Patel UD, Hernandez AF, Liang L, Peterson ED, LaBresh KA, Yancy CW, Albert NM, Ellrodt G, Fonarow GC: Quality of care and outcomes among patients with heart failure and chronic kidney disease: a Get With the Guidelines - Heart Failure Program study. Am Heart J 2008;156:674-681.

-3 Zannad F, Mebazaa A, Juilliere Y, Cohen-Solal A, Guize L, Alla F, Rouge P, Blin P, Barlet MH, Paolozzi L, Vincent C, Desnos M, Samii K: Clinical profile, contemporary management and one-year mortality in patients with severe acute heart failure syndromes: the EFICA study. Eur J Heart Fail 2006;8:697-705.

-4 Forman DE, Butler J, Wang Y, Abraham WT, O'Connor CM, Gottlieb SS, Loh E, Massie BM, Rich MW, Stevenson LW, Young JB, Krumholz HM: Incidence, predictors at admission, and impact of worsening renal function among patients hospitalized with heart failure. J Am Coll Cardiol 2004;43:61-67.

5 Lund LH, Edwards LB, Kucheryavaya AY, Dipchand AI, Benden C, Christie JD, Dobbels F, Kirk R, Rahmel AO, Yusen RD, Stehlik J: The Registry of the International Society for Heart and Lung Transplantation: Thirtieth Official Adult Heart Transplant Report - 2013; focus theme: age. J Heart Lung Transplant 2013;32:951-964.

6 Kirklin JK, Naftel DC, Pagani FD, Kormos RL, Stevenson LW, Blume ED, Miller MA, Timothy BJ, Young JB: Sixth INTERMACS annual report: a 10,000-patient database. J Heart Lung Transplant 2014;33:555-564.

7 Slaughter MS, Rogers JG, Milano CA, Russell SD, Conte JV, Feldman D, Sun B, Tatooles AJ, Delgado RM III, Long JW, Wozniak TC, Ghumman W, Farrar DJ, Frazier OH: Advanced heart failure treated with continuous-flow left ventricular assist device. N Engl J Med 2009;361:2241-2251.

8 Uriel N, Jorde UP, Woo PS, Jiang J, Clerkin K, Takayama H, Naka Y, Schulze PC, Mancini DM: Impact of long term left ventricular assist device therapy on donor allocation in cardiac transplantation. J Heart Lung Transplant 2013;32:188-195.

-9 Pal JD, Piacentino V, Cuevas AD, Depp T, Daneshmand MA, Hernandez AF, Felker GM, Lodge AJ, Rogers JG, Milano CA: Impact of left ventricular assist device bridging on posttransplant outcomes. Ann Thorac Surg 2009;88:1457-1461.

10 Stevenson LW, Pagani FD, Young JB, Jessup M, Miller L, Kormos RL, Naftel DC, Ulisney K, Desvigne-Nickens P, Kirklin JK: INTERMACS profiles of advanced heart failure: the current picture. J Heart Lung Transplant 2009; 28:535-541.

11 Mullens W, Abrahams Z, Francis GS, Sokos G, Taylor DO, Starling RC, Young JB, Tang WH: Importance of venous congestion for worsening of renal function in advanced decompensated heart failure. J Am Coll Cardiol 2009; 53:589-596.

-12 Welp H, Rukosujew A, Tjan TD, Hoffmeier A, Kosek V, Scheld HH, Drees G: Effect of pulsatile and non-pulsatile left ventricular assist devices on the renin-angiotensin system in patients with end-stage heart failure. Thorac Cardiovasc Surg 2010;58(suppl 2):S185-S188.

-13 Kihara S, Litwak KN, Nichols L, Litwak P, Kameneva MV, Wu Z, Kormos RL, Griffith BP: Smooth muscle cell hypertrophy of renal cortex arteries with chronic continuous flow left ventricular assist. Ann Thorac Surg 2003; 75:178-183.

14 Ohnishi H, Itoh T, Nishinaka T, Tatsumi E, Fukuda T, Oshikawa M, Shioya K, Tsukiya T, Takewa Y, Homma A, Uesho K, Sato K, Takano H, Taenaka Y: Morphological changes of the arterial systems in the kidney under prolonged continuous flow left heart bypass. Artif Organs 2002;26:974-979.

15 Ootaki C, Yamashita M, Ootaki Y, Kamohara K, Weber S, Klatte RS, Smith WA, Massiello AL, Emancipator SN, Golding LA, Fukamachi K: Reduced pulsatility induces periarteritis in kidney: role of the local renin-angiotensin system. J Thorac Cardiovasc Surg 2008;136:150-158.

16 Saito S, Nishinaka T, Westaby S: Hemodynamics of chronic nonpulsatile flow: implications for LVAD development. Surg Clin North Am 2004;84:61-74.

17 Thalmann M, Schima H, Wieselthaler G, Wolner E: Physiology of continuous blood flow in recipients of rotary cardiac assist devices. J Heart Lung Transplant 2005;24:237-245. 


\section{CardioRenal Medicine}

Coffin et al.: Kidney Dysfunction and Left Ventricular Assist Device Support:

A Comprehensive Perioperative Review

18 Iwashima Y, Yanase M, Horio T, Seguchi O, Murata Y, Fujita T, Toda K, Kawano Y, Nakatani T: Effect of pulsatile left ventricular assist system implantation on Doppler measurements of renal hemodynamics in patients with advanced heart failure. Artif Organs 2012;36:353-358.

19 Haglund NA, Feurer ID, Dwyer JP, Stulak JM, DiSalvo TG, Keebler ME, Schlendorf KH, Wigger MA, Maltais S: Does renal dysfunction and method of bridging support influence heart transplant graft survival? Ann Thorac Surg 2014;98:835-841.

20 Farrar DJ, Hill JD: Recovery of major organ function in patients awaiting heart transplantation with Thoratec ventricular assist devices. Thoratec Ventricular Assist Device Principal Investigators. J Heart Lung Transplant 1994;13:1125-1132.

21 James KB, McCarthy PM, Jaalouk S, Bravo EL, Betkowski A, Thomas JD, Nakatani S, Fouad-Tarazi FM: Plasma volume and its regulatory factors in congestive heart failure after implantation of long-term left ventricular assist devices. Circulation 1996;93:1515-1519.

22 Hasin T, Topilsky Y, Schirger JA, Li Z, Zhao Y, Boilson BA, Clavell AL, Rodeheffer RJ, Frantz RP, Edwards BS, Pereira NL, Joyce L, Daly R, Park SJ, Kushwaha SS: Changes in renal function after implantation of continuousflow left ventricular assist devices. J Am Coll Cardiol 2012;59:26-36.

23 Sandner SE, Zimpfer D, Zrunek P, Dunkler D, Schima H, Rajek A, Grimm M, Wolner E, Wieselthaler GM: Renal function after implantation of continuous versus pulsatile flow left ventricular assist devices. J Heart Lung Transplant 2008;27:469-473.

-24 Sandner SE, Zimpfer D, Zrunek P, Rajek A, Schima H, Dunkler D, Grimm M, Wolner E, Wieselthaler GM: Renal function and outcome after continuous flow left ventricular assist device implantation. Ann Thorac Surg 2009; 87:1072-1078.

25 Kamdar F, Boyle A, Liao K, Colvin-Adams M, Joyce L, John R: Effects of centrifugal, axial, and pulsatile left ventricular assist device support on end-organ function in heart failure patients. J Heart Lung Transplant 2009;28:352-359.

-26 Radovancevic B, Vrtovec B, de Kort E, Radovancevic R, Gregoric ID, Frazier OH: End-organ function in patients on long-term circulatory support with continuous- or pulsatile-flow assist devices. J Heart Lung Transplant 2007;26:815-818.

27 Park SJ, Milano CA, Tatooles AJ, Rogers JG, Adamson RM, Steidley DE, Ewald GA, Sundareswaran KS, Farrar DJ, Slaughter MS: Outcomes in advanced heart failure patients with left ventricular assist devices for destination therapy. Circ Heart Fail 2012;5:241-248.

28 Brisco MA, Kimmel SE, Coca SG, Putt ME, Jessup M, Tang WW, Parikh CR, Testani JM: Prevalence and prognostic importance of changes in renal function after mechanical circulatory support. Circ Heart Fail 2014;7: 68-75.

29 Demirozu ZT, Etheridge WB, Radovancevic R, Frazier OH: Results of HeartMate II left ventricular assist device implantation on renal function in patients requiring post-implant renal replacement therapy. J Heart Lung Transplant 2011;30:182-187.

-30 Starling RC, Naka Y, Boyle AJ, Gonzalez-Stawinski G, John R, Jorde U, Russell SD, Conte JV, Aaronson KD, McGee EC Jr, Cotts WG, DeNofrio D, Pham DT, Farrar DJ, Pagani FD: Results of the post-U.S. Food and Drug Administration-approval study with a continuous flow left ventricular assist device as a bridge to heart transplantation: a prospective study using the INTERMACS (Interagency Registry for Mechanically Assisted Circulatory Support). J Am Coll Cardiol 2011;57:1890-1898.

-31 Yoshioka D, Sakaguchi T, Saito S, Miyagawa S, Nishi H, Yoshikawa Y, Fukushima S, Saito T, Daimon T, Ueno T, Kuratani T, Sawa Y: Predictor of early mortality for severe heart failure patients with left ventricular assist device implantation: significance of INTERMACS level and renal function. Circ J 2012;76:1631-1638.

-32 Deo SV, Sharma V, Altarabsheh SE, Hasin T, Dillon J, Shah IK, Durham LA 3rd, Stulak JM, Daly RC, Joyce LD, Park SJ: Hepatic and renal function with successful long-term support on a continuous flow left ventricular assist device. Heart Lung Circ 2014;23:229-233.

-33 Kishimoto T, Maekawa M, Abe Y, Yamamoto K: Intrarenal distribution of blood flow and renin release during renal venous pressure elevation. Kidney Int 1973;4:259-266.

34 Ruggenenti P, Remuzzi G: Worsening kidney function in decompensated heart failure: treat the heart, don't mind the kidney. Eur Heart J 2011;32:2476-2478.

35 Ronco C, Di Lullo L: Cardiorenal syndrome. Heart Fail Clin 2014;10:251-280.

-36 Valika AA, Gheorghiade M: Ace inhibitor therapy for heart failure in patients with impaired renal function: a review of the literature. Heart Fail Rev 2013;18:135-140.

-37 McCullough PA: Contrast-induced acute kidney injury. J Am Coll Cardiol 2008;51:1419-1428.

38 Wu X, Zhang W, Ren H, Chen X, Xie J, Chen N: Diuretics associated acute kidney injury: clinical and pathological analysis. Ren Fail 2014;36:1051-1055.

-39 Ronco C, Cicoira M, McCullough PA: Cardiorenal syndrome type 1: pathophysiological crosstalk leading to combined heart and kidney dysfunction in the setting of acutely decompensated heart failure. J Am Coll Cardiol 2012;60:1031-1042.

-40 Borgi J, Tsiouris A, Hodari A, Cogan CM, Paone G, Morgan JA: Significance of postoperative acute renal failure after continuous-flow left ventricular assist device implantation. Ann Thorac Surg 2013;95:163-169.

41 Feldman D, Pamboukian SV, Teuteberg JJ, et al; International Society for Heart and Lung Transplantation: The 2013 International Society for Heart and Lung Transplantation Guidelines for mechanical circulatory support: executive summary. J Heart Lung Transplant 2013;32:157-187. 


\section{CardioRenal Medicine}

\begin{tabular}{l|l}
\hline \multicolumn{2}{l}{ Cardiorenal Med 2015;5:48-60 } \\
\hline DOI: $10.1159 / 000369589$ & $\begin{array}{l}\text { C 2015 S. Karger AG, Basel } \\
\text { www.karger.com/crm }\end{array}$ \\
\hline
\end{tabular}

Coffin et al.: Kidney Dysfunction and Left Ventricular Assist Device Support:

A Comprehensive Perioperative Review

42 Alba AC, Rao V, Ivanov J, Ross HJ, Delgado DH: Predictors of acute renal dysfunction after ventricular assist device placement. J Card Fail 2009;15:874-881.

43 Topkara VK, Dang NC, Barili F, Cheema FH, Martens TP, George I, Bardakci H, Oz MC, Naka Y: Predictors and outcomes of continuous veno-venous hemodialysis use after implantation of a left ventricular assist device. J Heart Lung Transplant 2006;25:404-408.

44 Genovese EA, Dew MA, Teuteberg JJ, Simon MA, Bhama JK, Bermudez CA, Lockard KL, Winowich S, Kormos RL: Early adverse events as predictors of 1-year mortality during mechanical circulatory support. J Heart Lung Transplant 2010;29:981-988.

-45 Vural KM: Ventricular assist device applications. Anadolu Kardiyol Derg 2008;8(suppl 2):117-130.

-46 Kellum JA, Lameire N; KDIGO AKI Guideline Work Group: Diagnosis, evaluation, and management of acute kidney injury: a KDIGO summary (part 1). Crit Care 2013;17:204.

-47 Finfer S, Bellomo R, Boyce N, French J, Myburgh J, Norton R: A comparison of albumin and saline for fluid resuscitation in the intensive care unit. N Engl J Med 2004;350:2247-2256.

48 Lowenstein J, Schacht RG, Baldwin DS: Renal failure in minimal change nephrotic syndrome. Am J Med 1981; 70:227-233.

49 Patel AM, Adeseun GA, Ahmed I, Mitter N, Rame JE, Rudnick MR: Renal failure in patients with left ventricular assist devices. Clin J Am Soc Nephrol 2013;8:484-496.

50 Slaughter MS, Pagani FD, Rogers JG, Miller LW, Sun B, Russell SD, Starling RC, Chen L, Boyle AJ, Chillcott S, Adamson RM, Blood MS, Camacho MT, Idrissi KA, Petty M, Sobieski M, Wright S, Myers TJ, Farrar DJ; HeartMate II Clinical Investigators: Clinical management of continuous-flow left ventricular assist devices in advanced heart failure. J Heart Lung Transplant 2010;29(suppl):S1-S39.

51 Lehman LW, Saeed M, Moody G, Mark R: Hypotension as a risk factor for acute kidney injury in ICU patients. Comput Cardiol 2010;37:1095-1098.

52 Hou FF, Zhang X, Zhang GH, Xie D, Chen PY, Zhang WR, Jiang JP, Liang M, Wang GB, Liu ZR, Geng RW: Efficacy and safety of benazepril for advanced chronic renal insufficiency. N Engl J Med 2006;354:131-140.

53 Hsu TW, Liu JS, Hung SC, Kuo KL, Chang YK, Chen YC, Hsu CC, Tarng DC: Renoprotective effect of renin-angiotensin-aldosterone system blockade in patients with predialysis advanced chronic kidney disease, hypertension, and anemia. JAMA Intern Med 2014;174:347-354.

54 Molnar MZ, Kalantar-Zadeh K, Lott EH, Lu JL, Malakauskas SM, Ma JZ, Quarles DL, Kovesdy CP: Angiotensinconverting enzyme inhibitor, angiotensin receptor blocker use, and mortality in patients with chronic kidney disease. J Am Coll Cardiol 2014;63:650-658.

55 Jennette JC, Falk RJ: Small-vessel vasculitis. N Engl J Med 1997;337:1512-1523.

56 Cox ZL, Calcutt MW, Morrison TB, Akers WS, Davis MB, Lenihan DJ: Elevation of plasma milrinone concentrations in stage D heart failure associated with renal dysfunction. J Cardiovasc Pharmacol Ther 2013;18:433-438.

-57 Rabindranath K, Adams J, Macleod AM, Muirhead N: Intermittent versus continuous renal replacement therapy for acute renal failure in adults. Cochrane Database Syst Rev 2007;3:CD003773.

58 Kidney Disease: Improving Global Outcomes (KDIGO) Acute Kidney Injury Work Group: KDIGO Clinical Practice Guideline for Acute Kidney Injury. Kidney Int Suppl 2012;2:1-141.

59 Bellomo R, Cass A, Cole L, Finfer S, Gallagher M, Lo S, McArthur C, McGuinness S, Myburgh J, Norton R, Scheinkestel C, Su S: Intensity of continuous renal-replacement therapy in critically ill patients. N Engl J Med 2009;361:1627-1638.

60 Palevsky PM, Zhang JH, O'Connor TZ, Chertow GM, Crowley ST, Choudhury D, Finkel K, Kellum JA, Paganini E, Schein RM, Smith MW, Swanson KM, Thompson BT, Vijayan A, Watnick S, Star RA, Peduzzi P: Intensity of renal support in critically ill patients with acute kidney injury. N Engl J Med 2008;359:7-20.

61 Guglielmi AA, Guglielmi KE, Bhat G, Siemeck R, Tatooles AJ: Peritoneal dialysis after left ventricular assist device placement. ASAIO J 2014;60:127-128.

62 Thomas BA, Logar CM, Anderson AE: Renal replacement therapy in congestive heart failure requiring left ventricular assist device augmentation. Perit Dial Int 2012;32:386-392.

63 Karamlou T, Welke KF, McMullan DM, Cohen GA, Gelow J, Tibayan FA, Mudd JM, Slater MS, Song HK: Combined heart-kidney transplant improves post-transplant survival compared with isolated heart transplant in recipients with reduced glomerular filtration rate: analysis of 593 combined heart-kidney transplants from the United Network Organ Sharing Database. J Thorac Cardiovasc Surg 2014;147:456-461.

64 Collins AJ, Foley RN, Herzog C, et al: US Renal Data System 2010 Annual Data Report. Am J Kidney Dis 2011; 57(suppl 1):A8, e1-e526.

65 Sumida M, Doi K, Kinoshita O, Kimura M, Ono M, Hamasaki Y, Matsubara T, Ishii T, Yahagi N, Nangaku M, Noiri E: Perioperative plasma neutrophil gelatinase-associated lipocalin measurement in patients who undergo left ventricular assist device implantation surgery. Circ J 2014;78:1891-1899.

66 Baldwin JT, Mann DL: NHLBI's program for VAD therapy for moderately advanced heart failure: the REVIVEIT pilot trial. J Card Fail 2010;16:855-858.

67 Farrar DJ: Risk assessment and comparative effectiveness of left ventricular assist device (LVAD) and medical management (ROADMAP). ClinicalTrials.gov identifier: NCT01452802. http://clinicaltrials.gov/ct2/show/ NCT01452802.

68 Barbone A, Pini D, Ornaghi D, Visigalli MM, Ardino L, Bragato R, Curzi M, Cioccarelli SA, Di Diodoro L, Basciu A, Cappai A, Settepani F, Citterio E, Cappelleri A, Calcagnino M, Mangiavacchi M, Tarelli G, Lettino M, Vitali E: CircuLite Synergy ventricular assist device: a new approach to end-stage congestive heart failure (in Italian). G Ital Cardiol (Rome) 2014;15:116-122. 
69 Umakanthan R, Haglund NA, Stulak JM, Joyce LD, Ahmad R, Keebler ME, Maltais S: Left thoracotomy HeartWare implantation with outflow graft anastomosis to the descending aorta: a simplified bridge for patients with multiple previous sternotomies. ASAIO J 2013;59:664-667.

-70 Demirozu ZT, Radovancevic R, Hochman LF, Gregoric ID, Letsou GV, Kar B, Bogaev RC, Frazier OH: Arteriovenous malformation and gastrointestinal bleeding in patients with the HeartMate II left ventricular assist device. J Heart Lung Transplant 2011;30:849-853.

71 Rojas SV, Avsar M, Khalpey Z, Hanke JS, Haverich A, Schmitto JD: Minimally invasive off-pump left ventricular assist device exchange: anterolateral thoracotomy. Artif Organs 2014;38:539-542.

-72 Schmitto JD, Rojas SV, Hanke JS, Avsar M, Haverich A: Minimally invasive left ventricular assist device explantation after cardiac recovery: surgical technical considerations. Artif Organs 2014;38:507-510.

73 Garcia SD, Mohite PN, Zych B, Sabashnikov A, Hards R, Simon AR, Bahrami T: Minimally invasive access for off-pump HeartWare left ventricular assist device explantation. Interact Cardiovasc Thorac Surg 2013;17: 581-582.

74 Ronco C, Haapio M, House AA, Anavekar N, Bellomo R: Cardiorenal syndrome. J Am Coll Cardiol 2008;52: 1527-1539. 